\title{
Architectural Engineering Applications of Rapid Prototyping
}

\author{
Michael J. McGeen, A.I.A. \\ Milwaukee School of Engineering
}

\begin{abstract}
In today's construction industry, with the introduction of new materials, free-form shapes of buildings, special problems with historical preservation and even buildings with very large components that move, there are many new challenges for the architectural engineer. This paper highlights some of the work done at Milwaukee School of Engineering that links the work of architectural engineers with our Rapid Prototyping Center. This work started as research under the Research Experience for Undergraduates in Solid Freeform Fabrication program at MSOE. This is a program sponsored by the National Science Foundation. Projects have ranged from replication of historical decorative plaster details and writing code to translate drawing files into a form that can be read by the RP machines to modeling a building designed for Milwaukee School of Engineering by Santiago Calatrava. A side benefit of this program has been realized in our Senior Design course, AE450, where student teams design a building for a real client. Models of these designs, which used to take at least three weeks to fabricate, are now completed sometimes in as little time as five days. This has proven to be a definite benefit to our clients as well as a better use of student time.
\end{abstract}

\section{Introduction}

This paper is a summary of work that has been on going at Milwaukee School of Engineering (MSOE). The strength of this work is the result of the collaboration between students and faculty from different academic backgrounds and departments. The common thread running through all of this research is that each department is looking for new ways to use rapid prototyping in their area of interest. We have students that have worked on such diverse topics as modeling the human skull, the circulatory system of rat lungs, devices for improved heat exchange and an experiment to be taken into space on the space shut tle. All of us have come together under a program made possible by a grant from the National Science Foundation (NSF) called Research Experiences for Undergraduates (REU) to share our discoveries in hopes that a new discovery or technique in one area might also find application in another discipline. This paper will specifically cover the application of rapid prototyping to the area of architectural engineering, or more specifically, the modeling of buildings or parts of buildings.

\section{The rationale for mode ling buildings}

The question that comes up most often from people not familiar with the practice of architecture is; why do you build models in the first place? The first reason an architect may have to create 
a model of a building very often is to test visually the assumptions he/she has made about a design during the design process and try alternative solutions. Although cutting mat board and foam core by hand can be tedious and time consuming, modeling in 3D allows a level of exploration that cannot be achieved with two-dimensional drawings. The added quality it brings to the design process is worth it.

Another very important reason to build models of buildings is that clients like models. They like to walk around them, hold them up and view the $m$ at eye level to visualize what it might be like to stand in front of the building. A model, if done well, can sell a design better than any drawing. At MSOE we use a number of computer aided design (cad) packages that can produce a virtual tour of a design project. A couple of years ago one of our student design teams proposed that they build a virtual model of their project and produce a movie "walk through" for final presentation to the client. The other three design teams presented physical models of the project. The cad model, rendered with lighting and materials, took about the same amount of time to build. In the end, however, the most striking feedback from the client was that it would have been nice if this team had made a model like the other three teams. So we have learned that a physical model is indispensable in helping to sell ideas to a client.

Another interesting area of architecture and rapid prototyping is the replication, preservation and restoration of historic ornamental detail on buildings. Use of molds to cast decorative plaster details for buildings has been around for ages. The potential to use rapid prototyping to create complex positive forms, as well as the negative form of the mold, is well understood in the manufacturing field. This information is now making it possible to replicate ornamental details in buildings with very little damage to the original.

In addition to the visual aspects of modeling buildings, there is the practical side of testing the building or its components for its engineered properties. Three of the projects listed in this paper explore the possibility of using a model, produced in the Rapid Prototyping Center, to test the structural properties of a building.

\section{The Problem with Architectural Drawings}

We have spent some time in the REU program looking at file formats that are used by AutoCad, because that seems to be the predominant software that is used by architects. It should be stated up front that there is a big difference in methodology between mechanical engineering graphics (machine parts) and architectural graphics (buildings). Machine parts, many times, are designed to be "solid" entities in cad programs. These solid entities translate very easily into the "stl" file format required for rapid prototyping machines. This is not the case with building design. Buildings today are still being produced with floor plans and section drawings that are twodimensional, 2-D lines and text. Cad packages such as AutoCad Architectural Desktop can produce 3-D drawings and render them with materials and light sources, but many of the drawing entities it uses do not translate into "stl" files without some extra programming. Why is this program written this way? AutoCad Architectural Desktop is written this way because buildings are assembled differently than machine parts. An exterior wall is an assembly of dozens of individual building components. It is not one homogenous material like a piece of machinery 
can be. Although AutoCad can draw solid entities that translate into "stl" files, architects seldom use this feature because it doesn't represent the true nature of how the building is assembled.

\section{Implementation}

It may be helpful at this point to describe the characteristics of some of the rapid prototyping (RP) machines here at Milwaukee School of Engineering.

The Stereolithography Machine (SLA) builds parts in a vat of light sensitive liquid resin. This resin is solidified (layer by layer) when it is exposed to the light from a laser. The Fused Deposition Modeling machine (FDM) builds an object by depositing resin in layers from a "glue gun" like device. The Laminated Object Manufacturing machine (LOM) can build objects out of many layers of resin-coated paper that is cut by a laser. This laser cuts out the profile of the piece being built, and cubes up the rest, to be removed after the piece is done. The Selective Laser Sintering (SLS) machine builds parts in a vat of powder that fuses together when it is hit by the laser. The laser engraver is more limited in capabilities. It is used to cut or etch flat material with a size limitation of 12 "x30" one piece at a time for hand assembly.

It is important to understand that all of the RP machines deal with this information in a similar manner. The part to be built must be made into a cad solid entity. The RP software then takes the "stl" file and slices it into layers and the RP machine then reassembles the layers as it builds the 3D part. Each of these RP machines, produce models with different characteristics but the common requirement for all of them is the "stl" file format. So the challenge in all of these projects is in acquiring, and translating, the data into a format that can be read by the RP machines.

\section{Some interesting solut ions}

\section{Senior design models}

Work with the Rapid Prototyping Center in the senior design area has been relatively straightforward. Our Architectural Engineering (AE) senior design students are split up into teams of 6 to 8 students each. With AE specialties of building electrical systems, building mechanical systems, structural design, and construction management divided equally among the teams. The series of three courses is team taught with faculty representing each of the engineering design specialties. All of the AE specialties take responsibility for the architectural design of the project. In the fall quarter, students meet with a client to write the program that will guide their design process. Architectural designs are completed in the winter quarter with a major presentation to the client occurring at the end of the $9^{\text {th }}$ week of our ten-week quarter. Producing the laser cut models is similar to planning plots on an older pen plotter. Elevation drawings must be planned to include information that can be exported to the laser cutter. The speed and intensity of the laser beam is controlled by color of line and only the lines that are to be burned by the laser can remain in this file. Each team is allotted ten hours of machine time, paid for by the Rapid Prototyping Center. This has proven in the past to be more than enough time to cut the models (figure 1). 


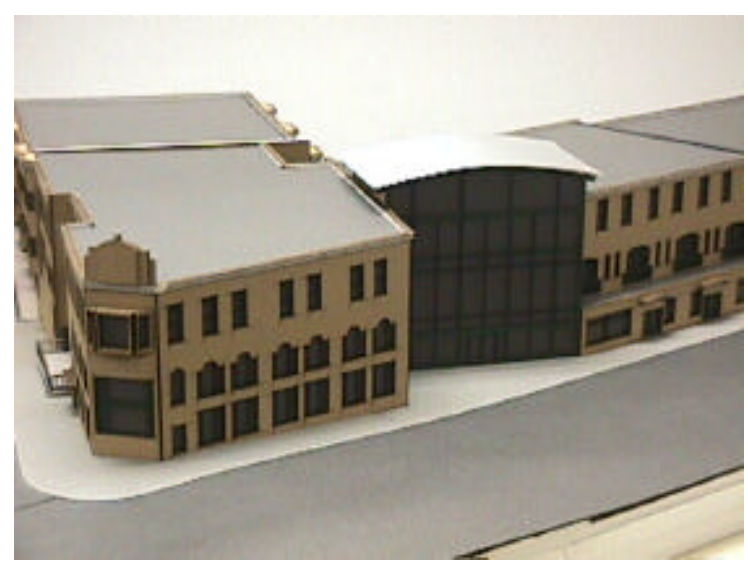

Figure 1

The laser engraver has been the RP Machine of choice for our architectural engineering teams working on their senior designs because the interface is easy to understand and it doesn't require too much change in the way they are already producing their drawings. Interest is building, however, and as student designs start to become more freeform, and as the cost of build time on the RP machines go down, it will be only a matter of time before some of the other machines are utilized here.

Replicating ornamental architectural details comes under the heading of data acquisition. In 1997 we began looking at some software that claimed to be able to create true 3D models from digital photographs. This sounded like just the ticket for modeling large buildings, as well as smaller architectural ornament found on buildings. This work was started by Golda Weir ${ }^{1}$ and was continued in the summer of 1997 by Kevin Tet $z$. In short, the process requires that an object be photographed from multiple angles with numbered dots placed on the surface. These photos are then imported into the program and the user then manually establishes the link between the corresponding dots in each view. Through triangulation, the software then can make the "stl" file to build the object in the rapid prototyping machine of choice. This method can work reasonably well if the object is relatively simple in shape and a high degree of precision is not required. Weir, who used a bronze sculpture of a head, found that the more freeform the shape, the more points are required to achieve an accurate representation. As the number of points increases, it becomes extremely difficult to physically match the points from one view to another. She referred to her model as the hockey mask because of the grotesque way the software interpreted her data.

Kevin Tet $z^{2}$, who continued the work that Weir started, looked more closely at the replication of architectural details in historical restoration. Traditionally, the replication of ornamental plaster detail is accomplished by applying a releasing agent directly on the original. A mold is then built around the original detail and after it sets up, one hopes that it doesn't pull the original plaster away when this mold is removed. A scary thought when dealing with old, sometimes unique, details. Unfortunately, the software that Weir and Tetz had been working with could not reproduce the detail required for historical restoration. Hitting this dead end, we turned to a company in Quebec, Canada, Laser InSpec, Inc. This company produces a camera that uses a projected grid of halogen light to capture a mesh consisting of tens of thousands of 3-D points. 
These points, with some manipulation, can be formed into a solid mesh and imported to RP machines. This camera, which uses a single lens, has been used extensively for capturing 3D elements to be used for special effects in Hollywood films.

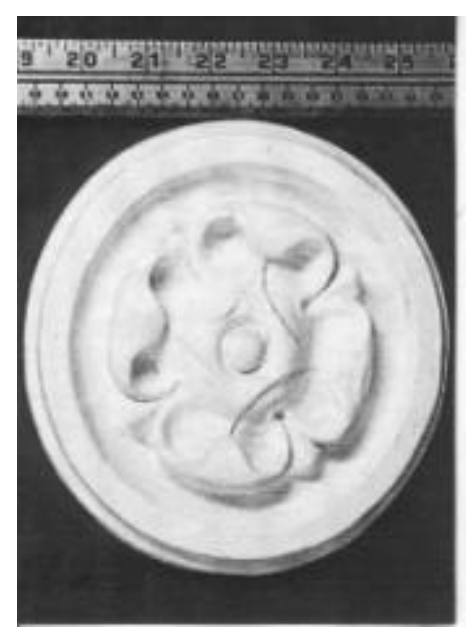

Figure 2

The rosette shown (figure 2) is a reproduction of an original detail loaned to us by Orlandini Studios, a company that specializes in designing and restoring historical plaster details. This system allows a copy to be made without removal of, or physically touching, the original in any way that would be destructive. Our copy was made on the LOM and a silicon rubber mold was made so that multiple copies could be made. This copy was made at a low resolution to save on computing time, and to prove the process. Images can be "photographed" at higher resolution to achieve a higher degree of smoothness in the final product. It should be pointed out that one drawback to this system is that this camera cannot image parts that are in the shadow of another. In other words, complex 3D parts with detail that is hidden to the camera lens will be simplified to only what the camera lens can see. There is a way, in theory, to take images from multiple angles and "stitch" them together to pick up this detail. Whether or not this is practical, and to what degree of accuracy the original part can be replicated, is a question that will have to be taken up with another researcher, since it turned out to be beyond the scope of what could be covered in Tetz's ten week session.

To date, the senior design projects have been completed mainly to provide a visual representation of the architectural features of a building. There are four projects here that have attempted to find a way to translate cad information into files that can be read by the RP machines. There exists, in archives, many cad drawings of buildings that could not be built by RP machines in their present form. There are reasons beyond just seeing a physical model to look at these buildings. Models of buildings can be wind tunnel tested either in an air elastic or static model form. These tests could be carried out in a more efficient way if there existed a quick way to translate traditional architectural cad drawings into an "stl" format. This story starts with Charity Rominger's ${ }^{3}$ work on translating cad files to "stl" format. Rominger chose the Sidney Opera House as a building to model because the file already existed as a sample AutoCad drawing. It is an interesting shape and this file is representative of many of the AutoCad drawing entities that typically do not translate into an "stl" format. 
Although Rominger's work did produce a model, much time was spent in converting the drawing manually. When looking at a drawing with thousands of entities and the tedious task of converting these entities manually, it becomes very clear that some other method is required to make it useful. Her work helped broaden our understanding of just what it would take to automatically translate drawings using a programming language.

Elen Koharian ${ }^{4}$, Elizabeth Brown ${ }^{5}$ and David Rodriguez ${ }^{8}$ all looked more closely at the drawing entities themselves and have come up with ways to automatically translate drawings. In other words, to look at the possibility of taking information directly from the AutoCad drawing database and re-building the shapes and volumes with "stl" compatible entities.

Koharian chose the roof superstructure for the Guangdong Olympic stadium. This building is very interesting on a number of levels. First of all, the structure is a two-way truss system that undulates in plan view (the $\mathrm{x}$ and $\mathrm{y}$ axis). It also undulates up and down in the $\mathrm{z}$-axis, while maintaining a constant thickness. The inspiration for this roof shape comes from the ribbon that is broken by the runner at the finish line and is blowing in the wind. The data we were able to obtain was a "stick" drawing of the roof structure that was used in the structural analysis program. Each structural member in this two-way truss system is reduced to a vector.

Koharian's goal was to write a program in LISP that would convert all of the lines in the drawing (over 4000 in the small section of roof we were working with) into cylinders. The cylinders could then be merged into one solid object and then built using the LOM. This program was written and has since been used to model and build other non-architectural models. Figure 3 shows the vector drawing and figure 4 shows the "STL" file ready to be sent to the LOM.

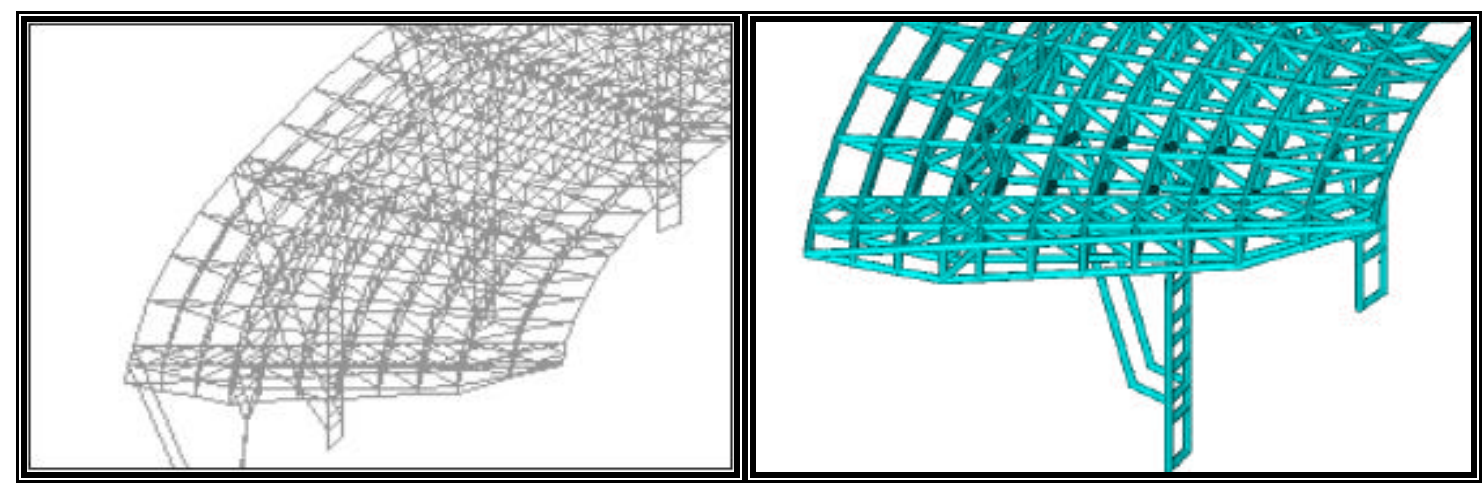

Figure 3

Figure 4

Elizabeth Brown ${ }^{5}$ continued the work that was started by Koharian. Whereas Koharian's program makes the assumption that all of the structural members are cylinders, Brown's program allows the user to build with profiles of structural steel shapes. Brown found that the added detail and rules required to place these structural steel profiles in the correct rotational orientation taxed both the rapid prototyping machines and our desktop computers ability to do the calculations. Brown's project yielded some smaller structures, but more could be done in this area in the future.

David Rodriguez ${ }^{8}$ looked at automatically translating nonsolid shell structures in AutoCad into "stl" files. Specifically, Rodriguez looked at 3D faces in AutoCad. A drawing like the Sidney Opera House is made up of hundreds of these entities that would need to be altered. Although

Proceedings of the 2002 American Society for Engineering Education Annual Conference \& Exposition Copyright (C) 2002, American Society for Engineering Education 
Rodriguez's paper has not yet been presented, he is slated to present his findings at the NCUR Conference in April 2002, at University of Wisconsin, Whitewater.

One very exciting aspect of prototyping architectural models and building components is the possibility of testing components in a lab before they are built. Areas of interest to the architectural engineer are wind tunnel testing of skyscrapers or uniquely shaped buildings, shaker table testing to predict behavior in an earthquake, and full field stress photography to predict areas of unusually high stress within a structure's members.

Jeff Bonnet's ${ }^{6}$ REU project in the summer of 2000 served multiple purposes. Architect Santiago Calatrava had just finished a preliminary design for the new Kern Health Center at Milwaukee School of Engineering (MSOE). Our president, Dr. Viets was interested in looking at some other alternatives for the plan of this building, as well as showing off the capabilities of the MSOE Rapid Prototyping Center. Bonnet, who is one of our structural engineering students, wished to look at methods of testing this buildings structure. The model (figure 6) shown below was built utilizing (4) different machines in our Rapid Prototyping Center. The most interesting RP machine on this project from the standpoint of structural testing is the laser engraver. Since we had no working drawings at this point to work from, the arches that we tested were assembled from the many original sketches (figure 5) Calatrava left with MSOE showing his design ideas. The concrete structural arches shown in the model were cut out of clear acrylic and photographed (see figure 7) with a special camera using polarized light. When this acrylic structural member is stressed, internal stress can then be read from the intensity of color on the photograph. Stress Photonics Inc. (a local company headquartered in Madison, Wisconsin) has done work for NASA and the automotive industry in analyzing parts, especially windshields. Figure 6 shows the site model, built by Bonnet, of the Calatrava design rendered in clear acrylic.

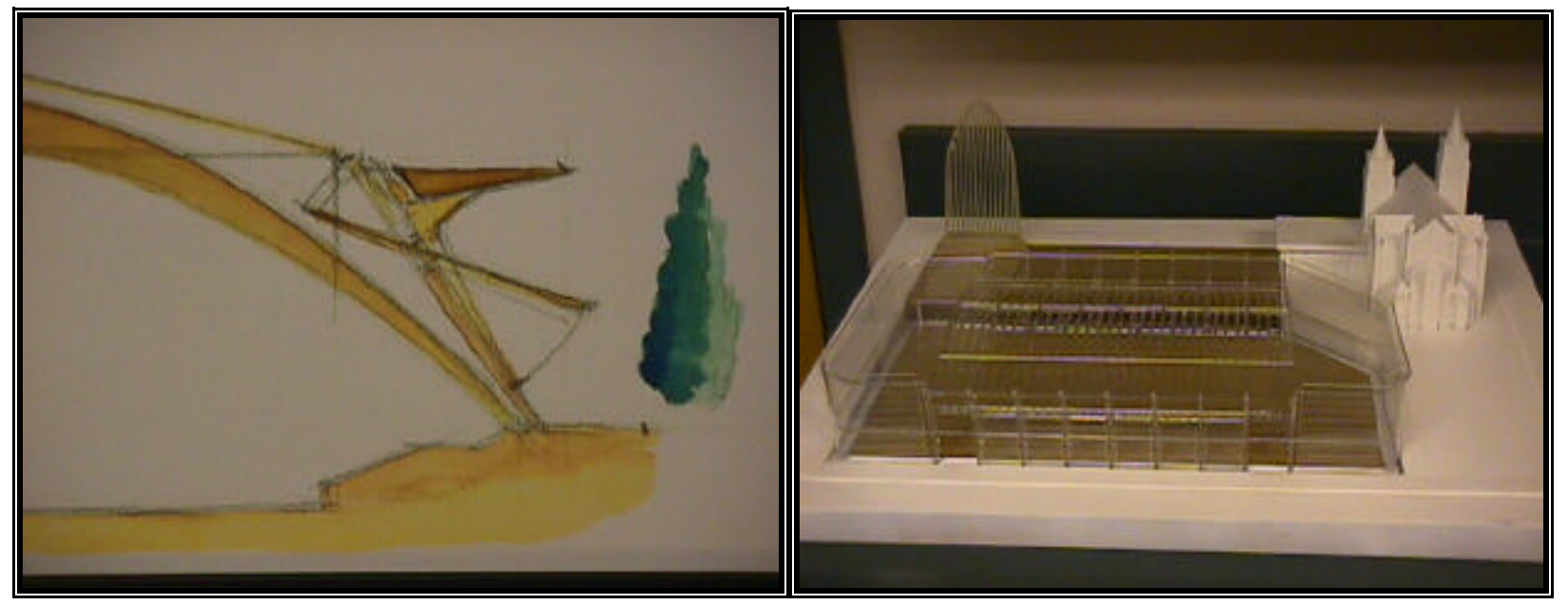

Figure 5

Figure 6 
Mike Marianek ${ }^{7}$ continued work in this area by exploring the design of a structure in Tokyo, Japan built of structural glass. The structure is a glass canopy that cantilevers 33 feet and covers a subway entrance in a city that is known to suffer earthquakes. This canopy is a unique structure made entirely of glass except for the steel pins that hold the glass together.

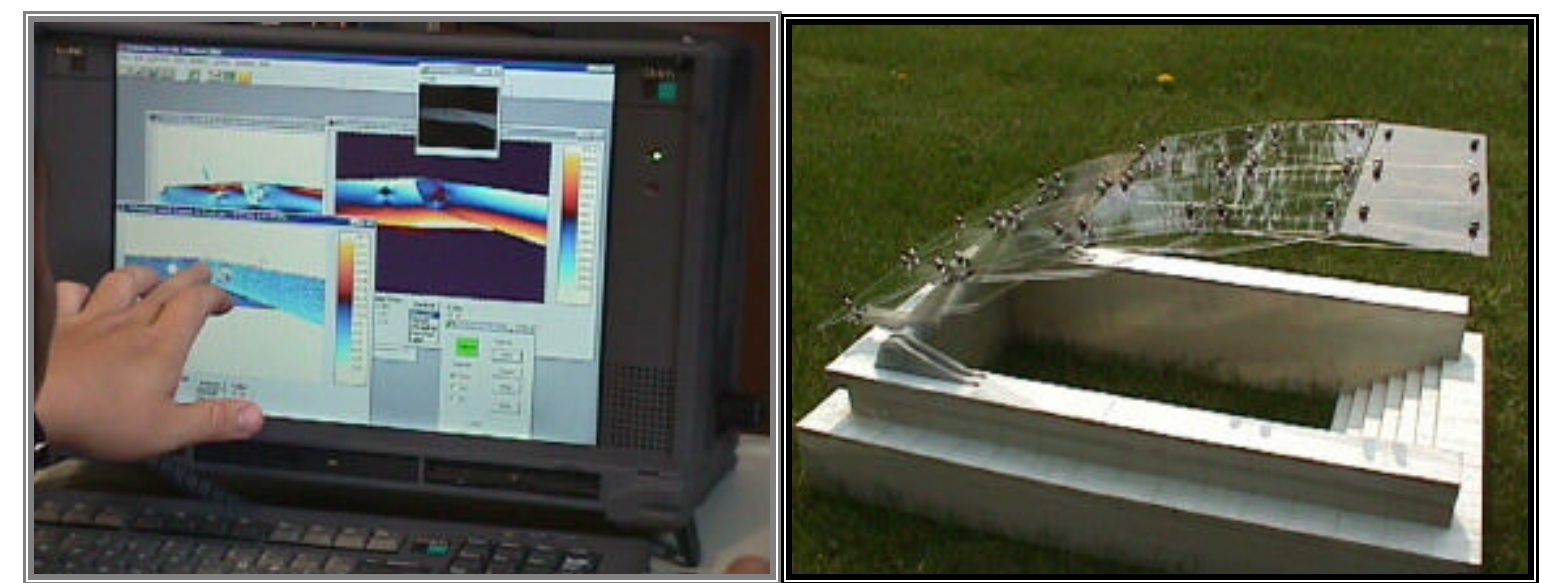

Figure 7

Figure 8

It is also interesting that this structure was designed utilizing full-scale mockups in a lab. This proved to be costly and time-consuming, but was required because it is a unique, one of a kind structure. Marianek's model (figure 8) was fabricated using the LOM, SLS and the laser engraver. The acrylic pieces were also analyzed using stress photography to look for internal "hot" spots around it's mounting holes, a critical consideration given the shape of the canopy and the structural properties of glass. This research has shown there is a correlation between the small-scale, acrylic model made in the RP Center and the actual structure. Although more work needs to be done in this area, this modeling technique may have been more cost effective in the preliminary design stages instead of the more costly full-scale mockups that were used in testing the structural integrity of this canopy.

So, where are we taking this in the future? This academic year, Marie Rieger $^{9}$, an electrical engineering student at MSOE, is looking at the possibility of capturing full field stress analysis images with a high-speed camera. Specifically, she hopes to be able to look at the internal stresses that occur in a model, in real time, during a seismic event. Rieger's work is not yet finished, but it has been accepted for presentation at the 2002 National Conference on Undergraduate Research in April of this year.

\section{Conclusions}

Rapid prototyping has already had a significant impact in the mechanical engineering area and is now making inroads to other areas. The professional lift that our students get when they are working on real projects for real clients is amazing. Since both programs, Research Experiences for Undergraduates (REU) and our Architectural Engineering degree program, use a multidisciplinary approach it is not unusual to have bio-med students and architectural engineering students brainstorming with mechanical engineering faculty about solid freeform fabrication of objects. Our clients have been pleased with the quality of our models as presentation pieces, but there is more that can be done. Judging by the work presented here, in 
the future our students will be leading the way in the use of Rapid Prototyping to routinely test models for wind and seismic compliance, as well as analyze internal stresses of building components under unusual stress conditions without the need of full-scale mock-ups.

\section{Bibliography}

1. Weir, G. Architectural Applications of Rapid Prototyping. 1999 National Conference on Undergraduate Research Conference Proceedings Rochester, New York, April 1999.

2. Tetz, K. Architectural Applications of Rapid Prototyping. 1999 National Conference on Undergraduate Research Conference Proceedings Rochester, New York, April 1999.

3. Rominger, C. Creating Models for Wind Tunnel Testing using Solid Freeform Fabrication1998-1999 REU in Solid Freeform Fabrication Research Papers MSOE, May 1999.

4. Koharian, E. A New Approach to Translating Architectural Drawings to an RP Compatible Format. 1999 REU in Solid Freeform Fabrication Research Papers MSOE, September 1999.

5. Brown, E. Conversion of Architectural Files for Modeling with Rapid Prototyping 2001 National Conference on Undergraduate Research Conference Proceedings Lexington, Kentucky, March 2001.

6. Bonnet, J. Architectural Modeling Using Rapid Prototyping. 2001 National Conference on Undergraduate Research Conference Proceedings Lexington, Kentucky, March 2001.

7. Marianek, M. Structural Glass Design Analysis Implementing Rapid Prototyping with Stress Photography. To be submitted to 2002 National Conference on Undergraduate Research Conference Proceedings Whitewater, Wisconsin, April 2002.

8. Rodriguez, D. New Approaches to Translating Architectural Drawings to an RP Compatible Format. 2001 REU in Solid Freeform Fabrication Research Papers MSOE, September 2001.

9. Rieger, M. Structural Analysis Aiding in the Design of Earthquake Resistant Architecture. To be submitted to 2002 National Conference on Undergraduate Research Conference Proceedings Whitewater, Wisconsin, April 2002. (Unpublished as of March 2002)

\section{MICHAEL MCGEEN}

Michael McGeen is an Associate Professor of AE\&BC at MSOE. He is active in the Rapid Prototyping Center at MSOE and has served as an adviser for the Research Experiences for Undergraduate program since 1998. Professor McGeen is a registered Architect with a Masters degree in Architecture from the University of Wisconsin - Milwaukee 